\title{
Seed priming alleviated salinity stress during germination and emergence of wheat (Triticum aestivum L.)
}

\author{
Faride Feghhenabi $^{\mathrm{a}}$, Hashem Hadi ${ }^{\mathrm{a}, *}$, Habib Khodaverdiloo ${ }^{\mathrm{b}}$, Martinus Th. van Genuchten ${ }^{\mathrm{c}, \mathrm{d}}$ \\ ${ }^{a}$ Department of Plant Production and Genetics, Urmia University, Urmia, Iran \\ ${ }^{\mathrm{b}}$ Department of Soil Science, Urmia University, Urmia, Iran \\ ${ }^{\mathrm{c}}$ Department of Earth Sciences, Utrecht University, Utrecht, the Netherlands \\ ${ }^{\mathrm{d}}$ Center for Environmental Studies, CEA, São Paulo State University, UNESP, Rio Claro, SP, Brazil
}

\section{A R T I C L E I N F O}

\section{Keywords:}

Potassium silicate

Salinity response functions

Seed priming

Seedling

Emergence

\begin{abstract}
A B S T R A C T
Seed priming is known to often alleviate salinity stress during seed emergence and subsequent crop growth. This study compares the effects of salinity stress on the germination and emergence of wheat (Triticum aestivum L.) seeds untreated (control) and primed with ascorbic acid (Asc), potassium silicate $\left(\mathrm{K}_{2} \mathrm{SiO}_{3}\right)$, proline (Pro), spermidine (Spd) and Lake Urmia saline water (LUsw). Saline water from Lake Urmia (Iran) was diluted to produce salinities with electrical conductivities $(E C)$ of $2,4,6,8,10,12,14,20 \mathrm{dS} \mathrm{m}^{-1}$, while distilled water (EC $\approx 0 \mathrm{dS} \mathrm{m}{ }^{-1}$ ) was used for the control. Two independent sets of experiments were conducted. The first experiments were used to select the most effective concentration of each priming agent based on the final germination percentage $(G P)$ and germination rate $(G R)$. The second set of experiments aimed to analyze the measured data in terms of salinity response functions in order to quantitatively determine the most effective priming agent(s). The first experiments showed that the most effective concentrations of Spd $(0.5 \mathrm{mM})$, Pro $\left(25 \mathrm{mM}^{2}, \mathrm{~K}_{2} \mathrm{SiO}{ }_{3}\right.$ $(1.5 \mathrm{mM})$ and LUsw $\left(100 \mathrm{mg} \mathrm{L}^{-1}\right)$ mitigated the negative impacts of salinity on $G R$ by $32,18,17$ and $22 \%$, respectively. The second experiment showed that the Maas and Hoffman (1977) and van Genuchten and Hoffman (1984) salinity response functions provided effective descriptions of seedling and early growth response to salinity stress. Mean values of the salinity threshold $\left(E C^{*}\right)$ and the salinity at which a given trait was reduced by 50 percent $\left(E C_{50}\right)$ in these functions were 3.4 and $10.8 \mathrm{dS} \mathrm{m}^{-1}$ for the control, respectively. By comparison, the $E C^{*}$ values for the $\mathrm{K}_{2} \mathrm{SiO}_{3}$, Pro, Spd and LUsw primed seeds were 5.3, 4.5, 4.7, and 4.2 $\mathrm{dS} \mathrm{m}^{-1}$, respectively, and the $E C_{50}$ values were $12.4,11.4,11.9$, and $9.4 \mathrm{dS} \mathrm{m}^{-1}$, respectively. The beneficial effects of $\mathrm{K}_{2} \mathrm{SiO}_{3}$ on seedling growth were more evident than those of the other priming agents. $\mathrm{K}_{2} \mathrm{SiO}_{3}$ had the highest effect on $E C^{*}$ and $E C_{50}$ of the vitality index $(V I)$, showing increases of 151 and $34 \%$, respectively. The highest increases of $E C^{*}$ and $E C_{50}$ for seedling dry weight (72 and $24 \%$, respectively) were obtained with Spd and $\mathrm{K}_{2} \mathrm{SiO}_{3}$. The findings provide much insight on relieving the negative effects of salinity through cost-effective seed priming operations so as to improve the production of wheat under saline conditions.
\end{abstract}

\section{Introduction}

Soil salinity causes major losses in crop production, especially in arid and semi-arid regions where 110 million out of 270 million ha of irrigated lands are located (Smedema and Shiati, 2002). Salinity is becoming more extensive as a result of land clearing and unsustainable irrigation and salinity management practices, as well as increasingly by bringing marginal lands into production (Kang et al., 2013; Munns and Gilliham, 2015; Kopittke et al., 2019). Salinity stress causes plants exposed to three major challenges, including increasing osmotic pressure, misbalancing ion uptake, and oxidative stress (Tahjib-Ul-Arif et al.,
2018). The response to this stress at each stage of growth varies not only among plant species, but also among cultivars (Bojović et al., 2010). Most crop species are sensitive to salinity stress at early growth stages, including the germination and seedling establishment stages (Wang et al., 2009). During germination and emergence, plant survival is likely the most vital indicator of salinity tolerance, whereas afterwards yield and growth reduction may be considered as the final tolerance criterion (Saadat and Homaee, 2015). The severity of salinity stress is often determined best by measuring seedling growth since rapid and uniform seedling emergence is a crucial prerequisite to achieve full yield potential and, ultimately, maximum profitability of

\footnotetext{
* Corresponding author.

E-mail address: h.hadi@urmia.ac.ir (H. Hadi).
} 
annual crops (Sadeghi and Robati, 2015).

There are several strategies to improve plant growth in salinity-affected environments. One strategy is through selection and breeding. Numerous attempts have been made to improve the salt tolerance of crops using traditional breeding programs. Unfortunately, the complexity of the basic tolerance mechanisms involved, a lack of optimal selection criteria, and variations in plant response to salinity at different growth stages have resulted in limited commercial success (Taie et al., 2013). Another strategy is to prime the seeds with different agents and/ or to use exogenous applications of these materials prior to their planting (Ali et al., 2017; Subramanyam et al., 2019). Many advocate for this purpose the use of seed priming as a practical, cost-effective, and low-risk alternative to improve seed germination and seedling emergence by inducing the metabolic activity of pre-germination under adverse conditions (Jiménez-arias et al., 2015; Migahid et al., 2019).

Priming is not a simple emulation of the early imbibition stage of germination, but rather is thought to impose moderate stress on seeds, which then activates a stress-responsive system that confers a "cross tolerance" on seeds when exposed to future stresses (Bhanuprakash and Yogeesha, 2016). During pre-germination metabolic activities, structural (membrane protection during imbibition) and genetic repair, RNA and protein synthesis and antioxidant mechanism take place in primed seed, which ensure its proper germination and seedling development (Saddiq et al., 2019). Several compounds such as silicon (Si), ascorbic acid (Asc), salicylic acid (SA), and polyamines (PAs), have been proposed as signal transducers and messengers, if used as a leaf spray or soil nutrient, or for seed priming, they may have profound effects on plant growth and development (Abu El-Soud et al., 2013; Kovácik et al., 2009). For example, proline is an organic osmolyte which if used as a seed priming, has been shown to enhance the $G R$ and relative germination energy ( $R G E$ ) of salinity-stressed rice seeds (Hua-long et al., 2014). Spermidine (Spd), a low-molecular-weight aliphatic amine, similarly improved $G P$, germination vigor, root viability and length, while shortening the mean germination time under different water stress conditions ( $\mathrm{Li}$ et al., 2014). Ascorbic acid is one of the most important antioxidants in plants that alleviates different environmental stresses. Silicon, the second most abundant mineral element on earth, furthermore has been found to enhance markedly the capacity of antioxidants and to improve protein metabolism to moderate oxidative stress (Geng et al., 2018).

Wheat (Triticum aestivum L.), which is one of the most important food crops in many parts of the world, often also suffers from salinity (Tuna et al., 2008). Numerous studies have noted the potential of seed priming to ameliorate the effects of salinity stress on wheat growth (Bajwa et al., 2018; Jaafer et al., 2012; Saddiq et al., 2019). However, there are differences in the response of wheat varieties to salinity and seed priming. Moreover, little quantitative information exists about the resistance of wheat during germination and seedling emergence, especially about the possible effects of salinity and seed priming at the seedling stage.

Over the years, a number of salinity response functions have been proposed for modeling plant tolerance to abiotic stresses, including plant response to salinity stress (e.g., Maas and Hoffman, 1977; van Genuchten and Hoffman, 1984). To our knowledge, such functions have not been generally used to assess the effects of seed priming on plant response to salinity stress. In this study we will apply the empirical response functions of Maas and Hoffman (1977) and van Genuchten and Hoffman, 1984) to identifying the most effective seed priming agents for lessening the effects of different salinity levels (up to $20 \mathrm{dS} \mathrm{m}^{-1}$ ) at the seedling stage. Specific objectives hence are to 1) investigate the ability of five different seed priming agents, notably spermidine (Spd), ascorbic acid (Asc), proline (Pro), potassium silicate $\left(\mathrm{K}_{2} \mathrm{SiO}_{3}\right)$ and Lake Urmia saline water (LUsw), to improve the germination potential of wheat (Triticum aestivum $\mathrm{L}$.) subject to salinity stress, and 2) quantify the response of wheat to salinity using response functions to investigate the performance of the seed priming agents at the seedling stage.

\section{Materials and methods}

All experiments were carried out at the Seed Technology Laboratory of the Agricultural Faculty of Urmia University (Urmia, Iran) during 2017. Wheat seeds (of the Chamran variety of Triticum aestivum L.) were provided by the Cereal Laboratory of the Agricultural Research Center of West Azerbaijan Province, Urmia, Iran. Mean seed dry weight per 100 seeds was $3.57 \mathrm{~g}$, while the seed moisture content ranged from 9 to $10 \%$. Separate studies prior to the experiments showed that seeds exhibited a $100 \%$ germination percentage at a temperature of $25^{\circ} \mathrm{C}$ as assessed using Petri dishes. The seeds were surface-sterilized in a $1 \%$ sodium hypochlorite solution for $10 \mathrm{~min}$, then rinsed with distilled water and dried before being used in the germination tests.

The experiments were implemented in two consecutive phases. The first phase aimed to evaluate the final germination percentage $(G P)$ and germination rate $(G R)$ of the seeds. This enabled us to obtain some preliminary data regarding plant response to different concentrations of the various seed priming agents (and for a control using untreated seeds) at the imposed salinity levels. The experiments allowed us to select the best concentrations of the various seed priming agents to be used for the next phase. For the priming we soaked the seeds into solutions containing spermidine (Spd) $(0,0.5,1$ and $1.5 \mathrm{mM})$ for $10 \mathrm{~h}$, ascorbic acid (Asc) $(0,50,75$ and $100 \mathrm{mM})$ for $24 \mathrm{~h}$, or proline (Pro) $(0$, $12,17$ and $20 \mathrm{mM})$ for 2 days, potassium silicate $\left(\mathrm{K}_{2} \mathrm{SiO}_{3}\right)(0,1,1.5$ and $2 \mathrm{mM}$ ) for $6 \mathrm{~h}$, or Lake Urmia saline water (LUsw) $(0,100,150$ and $200 \mathrm{mg} \mathrm{L}^{-1}$ salt) for $10 \mathrm{~h}$. These materials and their specific concentrations were selected following previous studies using similar agents (Ahmed et al., 2016; Ibrahim, 2016; Sivritepe et al., 2003; Torabi et al., 2012). Also, we note that Lake Urmia water was used, rather than artificial solutions, since the ionic solution composition of most nearby soils were fairly similar to that of the lake. Once primed, the seeds were thoroughly rinsed with tap water followed by distilled water, dried back to their original moisture content at room conditions (about $25^{\circ} \mathrm{C}$ and $42 \%$ relative humidity) as determined by changes in seed weight. All seeds subsequently were surface-sterilized in a $1 \%$ sodium hypochlorite solution for $10 \mathrm{~min}$ for use in the main experiments.

For the first phase we used nine salinity levels with electrical conductivities of $0,2,4,6,8,10,12,14$ and $20 \mathrm{dS} \mathrm{m}^{-1}$. The salinity levels were obtained by diluting saline water from Lake Urmia located in northwest Iran. Samples of 300 treated seeds (three replicates of 100 seeds) were placed in covered 9-cm diameter Petri dishes containing a single filter paper moistened with $7 \mathrm{ml}$ of each saline water treatment. The Petri dishes were placed in a germinator at $25 \pm 2{ }^{\circ} \mathrm{C}$. Data were collected every $6 \mathrm{~h}$ until no additional germination occurred for $48 \mathrm{~h}$. At the end of the experiments, the final GP and GR values were calculated after Sajirani et al. (2011). GR is generally considered to be the most important criterion since it reflects the vigor of the seeds. The most efficient concentration of every seed priming agent was selected from a linear regression of a particular trait (such as GP or GR) versus salinity. The concentration of a given priming agent that provided a regression line with the lowest slope was presumed to be the most effective concentration of that priming agent (Maggio et al., 2004; Steppuhn et al., 2005), and then used in subsequent experiments.

The second phase of the experiments was used to test, for each optimal concentration of the agents, the effects of the same range of salinities on seedling development over a period of 14 days. These experiments were carried out in a greenhouse having a temperature of approximately $25{ }^{\circ} \mathrm{C}$ during the day and $20^{\circ} \mathrm{C}$ at night, a relative humidity of $50 \pm 10 \%$, and a light intensity of $700 \mu \mathrm{mol} \mathrm{m} \mathrm{m}^{-2} \mathrm{~s}^{-1}$. We used for these experiments 16-cm high, 7-cm diameter PVC pots packed with $540 \mathrm{~g}$ farm soil. The loam soil (sand, silt and clay percentages were 46,33 and $21 \%$, respectively) was non-saline (the electrical conductivity of the saturation paste was $1.1 \mathrm{dS} \mathrm{m}^{-1}$ ), contained $18.5 \%$ 
equivalent $\mathrm{CaCO}_{3}$, and had a pH of 7.7. We sowed 10 seeds per pot, which were thinned to 5 seedlings per pot after emergence. For every treatment we used three replicates, thus providing us with data from 270 different pots (5 priming agents, 9 salinities, 2 phases, 3 replicates).

The various experiments produced estimates of the following traits:

Final maximum seed emergence percentage, $\boldsymbol{E}_{\max }$, being the ratio of the number of seeds emerged over the total number of seeds sown $(\times 100 \%)$.

Emergence rate, $\boldsymbol{R}_{\mathbf{5 0}}$, being the rate at which $50 \%$ of the seeds emerged: $R_{50}=1 / D_{50}$, where $D_{50}$ is the number of days needed to reach $50 \%$ of emergence.

Vitality index, VI, given by the length of the seedlings $\times E_{\max }$

Reciprocal of the emergence uniformity, $R E U$, given by $R E U=1 / E U$ where $E U=D_{90}-D_{10} . D_{10}$ and $D_{90}$ are the number of days needed to reach 10 and $90 \%$ emergence, respectively. As the difference between $D_{10}$ to $D_{90}$ increases, the emergence uniformity (EU) hence decreases and $R E U$ increases.

Seedling growth indexes given by certain seedling attributes such as length, dry weight and fresh weight 16 days after planting.

Weight of mobilized seed reserve, WMSR, given by the dry weight of the original seed minus the dry weight of the seed remnant. The initial seed dry weight was found to be $0.033 \pm 0.006 \mathrm{~g}$ per seed.

The effects of seed priming and salinity on the various traits were investigated using several empirical salinity response functions. Traditionally the most popular response function has been the linear threshold slope model introduced by Maas and Hoffman (1977). Written in terms of the soil electrical conductivity, $E C$, this response model is given by

$\alpha(E C)=\left\{\begin{array}{cl}1 & 0 \leq E C \leq E C^{*} \\ 1-b\left(E C-E C^{*}\right) & E C^{*}<E C \leq E C^{*}+1 / b \\ 0 & E C>E C^{*}+1 / b\end{array}\right.$

where $\alpha$ is the specific trait being considered in relative terms $(0 \leq \alpha \leq 1)$ as a function of soil salinity, $E C\left(\mathrm{dS} \mathrm{m} \mathrm{m}^{-1}\right), E C^{*}$ is the salinity threshold value and $b$ is the slope of the response function. Since the linearity assumption of Eq. (1) often does not fully meet actual field conditions, van Genuchten and Hoffman (1984) proposed an alternative S-shaped function of the form:

$\alpha(E C)=\frac{1}{1+\left(E C / E C_{50}\right)^{p}}$

where $E C_{50}$ is the soil salinity at which $\alpha(E C)$ is reduced by 50 percent, and $p$ is a dimensionless shape parameter, presumably a function of specific crop, soil and climate conditions. For many crops, the value of $p$ on average was found to be about 3 when Eq. (2) was applied to salinity stress data (van Genuchten and Gupta, 1993). As shown by Steppuhn et al. (2005) and van Genuchten and Gupta (1993), among others, Eq. (2) was found to describe crop salt tolerance data equally well or better than Eq. (1).

Dirksen et al. (1993) later included a threshold salinity in Eq. (2) to enable a more flexible description of salinity response data at low salinities:

$\alpha(E C)=\left\{\begin{array}{c}1 \quad 0 \leq E C \leq E C^{*} \\ \frac{1}{1+\left[\left(E C-E C^{*}\right) /\left(E C_{50}-E C^{*}\right)\right]^{p}} E C>E C^{*}\end{array}\right.$

The above macroscopic response functions were fitted to the observed data by minimizing the sum of the squared errors (SSE) between measured $\left(O_{i}\right)$ and model-predicted $\left(P_{i}\right)$ values of the dependent variable using unweighted least-squares regression (e.g., van Genuchten, 1983):

$S S E=\sum_{i=1}^{n}\left(P_{i}-O_{i}\right)^{2}$

where $n$ is number of data-points. Since the response functions have different numbers of fitting parameters, and more fitting parameters normally will lead to a better fit (i.e. lower SSE values), the Akaike information criterion (AIC) was used to compare the performance of the models. When the number of data-points $(n)$ is small in comparison to the number of fitting parameters $(q)$, such as in our study where $n$ exceeds the number of fitting parameters by only four or five, one may use the corrected AIC (Bolster and Hornberger, 2007; Razzaghi et al., 2016) as follows:

$A I C=n \ln \left(\frac{S S E}{n}\right)+2(q+1)+\frac{2(q+1)(q+2)}{n-q-2}$

The response function with the lowest value of AIC will be assumed to be the most accurate. To test if the improved accuracy is statistically sound and justifies the extra parameters, the probability will be calculated using (Bolster and Hornberger, 2007; Razzaghi et al., 2016):

$P=\frac{e^{0.5 \Delta}}{1+e^{0.5 \Delta}}$

in which $\Delta$ is the absolute difference between the AIC values of the two response functions being evaluated. $P$ values were used to ensure that the decrease in SSE, required to accept the more accurate response function, is reasonable (Bolster and Hornberger, 2007; Razzaghi et al., 2016).

Statistical operations, calculations, and fitting of response function models were performed using Excel 2013 software and its Solver extension.

\section{Results and discussion}

\subsection{Seed germination as influenced by salinity and priming}

The germination percentage $(G P)$ and germination rate $(G R)$ were both found to decrease with increasing salinity levels for both the control and the primed seeds (Figs. 1 and 2). However, the impact of salinity on $G R$ was higher than on GP, with GR showing an almost $50 \%$ reduction at $E C=20 \mathrm{dS} \mathrm{m}^{-1}$, while $G P$ decreased by only $23 \%$. Actually, $20 \%$ of the total reduction in GP occurred between 2 and $8 \mathrm{dS} \mathrm{m}^{-}$ ${ }^{1}$, while this amount was $45 \%$ for $G R$. The main reasons for the higher sensitivity of $G R$ to salinity as compared to GP could be attributed to the damages that salinity causes to the enzymes involved in germination or the delay in their activity (KhoshKholgh Sima et al., 2013). Except for Asc, all seed priming agents alleviated the inhibitory effect of salinity stress on GP and GR. Many studies have shown that a capability to rapidly re-start both Asc biosynthesis and APX activity is necessary for successful seed germination. However, other studies (e.g., Takemura et al., 2010) acknowledged that high Asc treatment may cause the

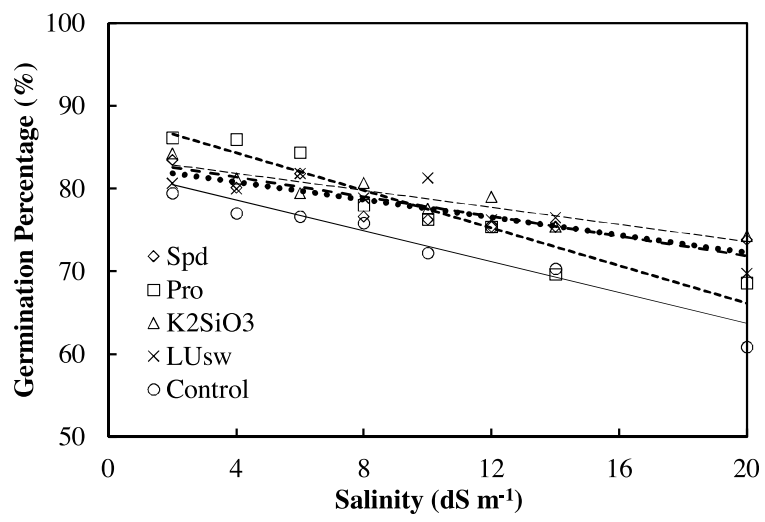

Fig. 1. Effect of salinity on the germination percentage of wheat untreated (Con, control) or primed with the most effective concentrations of the seed priming agents Spd (spermidine), Pro (proline), $\mathrm{K}_{2} \mathrm{SiO}_{3}$ (potassium silicate) and LUsw (Lake Urmia saline water) used in this study. 


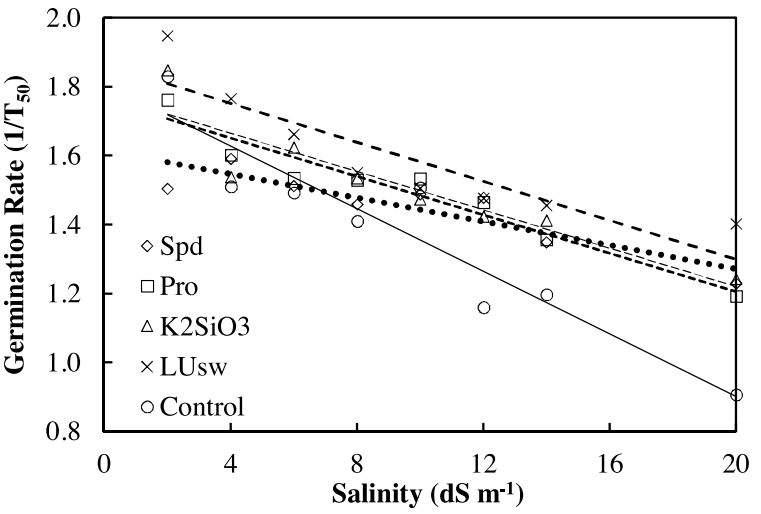

Fig. 2. Effect of salinity on the germination rate of wheat untreated (Con, control) or primed with the most effective concentrations of the seed priming agents Spd (spermidine), Pro (proline), $\mathrm{K}_{2} \mathrm{SiO}_{3}$ (potassium silicate) and LUsw (Lake Urmia saline water) used in this study.

destruction of mesothelioma cells and prevent germination in wheat seeds (Takemura et al., 2010). In agreement with these results, not only did none of the concentrations of Asc in our study have a positive effect, they actually reduced markedly the GP.

The priming concentrations that produced the lowest reduction (less negative slope) (Maggio et al., 2004; Steppuhn et al., 2005), and hence most likely the highest increases in the $G R$ and $G P$ values, were used in subsequent experiments. Ultimately, selected concentrations were $0.5 \mathrm{mM}$ for Spd, $25 \mathrm{mM}$ for Pro, $1.5 \mathrm{mM} \mathrm{K}_{2} \mathrm{SiO}_{3}$, and $100 \mathrm{mg} \mathrm{L}^{-1}$ for LUsw (Figs. 1 and 2). The most effective concentrations of Spd, Pro, $\mathrm{K}_{2} \mathrm{SiO}_{3}$ and LUsw mitigated the negative impacts of salinity on $G R$ by $32,18,17$ and $22 \%$, respectively, with their moderating effect on GP always being less than $15 \%$ (up to $3,11,11$ and $9 \%$, respectively). Seed priming hence had far more effect on the wheat germination rate than on the germination percentage. Experimentally, higher $G R$ values of primed seeds are due to metabolic repair, with more metabolite production required for germination during the imbibition process (Saddiq et al., 2019). Moreover, Hua-Long et al. (2014) showed that the improvement of $G R$ for primed seeds with Pro was mainly due to an increase in intracellular osmolytes and alleviation of water uptake imbalances during germination phases II and III.

\subsection{Seedling emergence as influenced by salinity and priming}

Salinity had a major inhibitory effect on the growth and development of seedlings as shown in Fig. 3, which provides results for the four most important traits we investigated. Quantitative parameters representing the effects of salinity on seedling growth and development are listed in Table 1 for all traits. Please note that all values in Fig. 3 are relative, calculated as the value of the attribute for each level of treatment (salinity and seed priming) relative to the control (i.e., the value at zero salinity and without seed priming). Hence, every value simultaneously reflects the coupled effects of salinity and seed priming. The responses of the traits versus salinity were almost the same. However, the intensities of the responses to salinity were not the same among all salinity levels. The effects at lower levels of salinity were generally milder, with most traits showing a negligible change up to certain threshold salinity, while the inhibitory effects of salinity on the traits increased beyond a certain threshold salinity (Fig. 3a-d). For example, the relative values of $E_{\max }$ and $R_{50}$ changed slightly to $E C=12$ and $4 \mathrm{dS} \mathrm{m}^{-1}$, respectively, after which they declined by almost 87 and $82 \%$, respectively, to $E C=20 \mathrm{dS} \mathrm{m}^{-1}$. In the same way, for all of the seed priming agents, the values of the traits decreased only modestly at low salinities. The changes were greater at higher salinities. It seems that the behavioral patterns of the traits versus salinity did not change much by seed priming. However, the rate of decrease and the
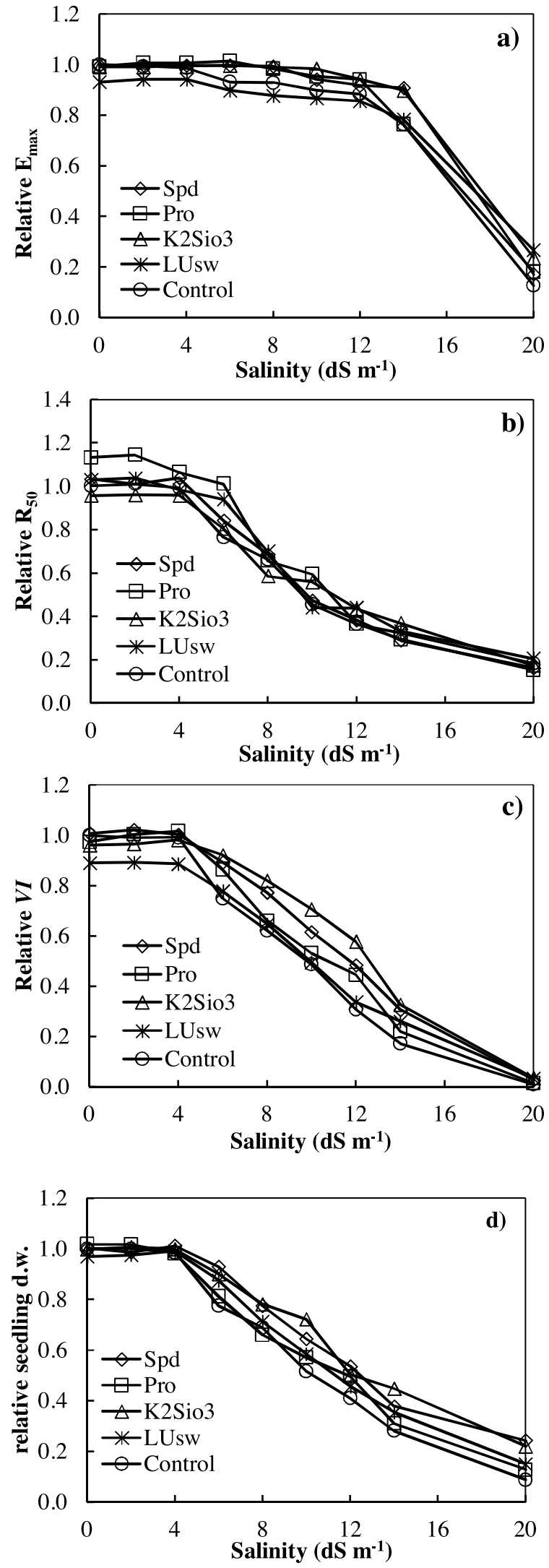

Fig. 3. Effect of salinity on relative values of $E_{\max }$ (a), $R_{50}$ (b), VI (c) and seedling dry weight (d) of wheat untreated (Con, control) or primed with the most effective concentrations of the seed priming agents seed priming agents Spd (spermidine), Pro (proline), $\mathrm{K}_{2} \mathrm{SiO}_{3}$ (potassium silicate) and LUsw (Lake Urmia saline water) used in this study. 
Table 1

Obtained values of parameters in the van Genuchten and Hoffman (1984) and Maas and Hoffman (1977) salinity response functions to quantitatively show the effect of various priming agents used in this study to cope with salinity stress.

\begin{tabular}{|c|c|c|c|c|c|c|}
\hline \multirow[t]{2}{*}{ Trait $^{1}$} & \multirow[t]{2}{*}{ Parameter $^{2}$} & \multicolumn{5}{|c|}{ Seed priming agent ${ }^{3}$} \\
\hline & & Control & Pro & $\mathrm{K}_{2} \mathrm{SiO}_{3}$ & Spd & LUsw \\
\hline \multirow[t]{4}{*}{$E_{\max }(\%)$} & $E C^{*}$ & 12.3 & 16.2 & 16.2 & 15.4 & 14.5 \\
\hline & $b$ & 0.106 & 0.202 & 0.194 & 0.172 & 0.113 \\
\hline & $E C_{50}$ & 16.2 & 16.4 & 17.7 & 17.3 & 17.7 \\
\hline & $p$ & 8.6 & 7.7 & 9.3 & 10.7 & 7.2 \\
\hline \multirow[t]{4}{*}{$R_{50}$ (1/day) } & $E C^{*}$ & 1.6 & 1.9 & 2.1 & 1.8 & 2.0 \\
\hline & $b$ & 0.051 & 0.062 & 0.048 & 0.055 & 0.053 \\
\hline & $E C_{50}$ & 9.7 & 9.7 & 10.8 & 9.9 & 10.3 \\
\hline & $p$ & 2.5 & 3.0 & 2.4 & 2.9 & 2.7 \\
\hline \multirow[t]{4}{*}{$R E U$ (1/day) } & $E C^{*}$ & 0.0 & 0.0 & 2.0 & 2.5 & 0.0 \\
\hline & $b$ & 0.048 & 0.039 & 0.065 & 0.050 & 0.053 \\
\hline & $E C_{50}$ & 8.6 & 8.3 & 8.6 & 9.1 & 7.6 \\
\hline & $p$ & 2.6 & 1.9 & 3.8 & 2.9 & 2.2 \\
\hline \multirow[t]{4}{*}{$V I$} & $E C^{*}$ & 2.2 & 3.5 & 5.6 & 3.8 & 3.4 \\
\hline & $b$ & 0.061 & 0.064 & 0.066 & 0.063 & 0.056 \\
\hline & $E C_{50}$ & 9.3 & 10.3 & 12.5 & 11.3 & 10.5 \\
\hline & $p$ & 3.4 & 3.6 & 5.1 & 3.9 & 3.7 \\
\hline \multirow[t]{4}{*}{ Seedling length $(\mathrm{cm})$} & $E C^{*}$ & 2.6 & 3.3 & 5.2 & 3.5 & 3.6 \\
\hline & $b$ & 0.060 & 0.058 & 0.058 & 0.056 & 0.055 \\
\hline & $E C_{50}$ & 9.9 & 10.7 & 12.9 & 11.8 & 11.2 \\
\hline & $p$ & 3.4 & 3.2 & 4.1 & 3.2 & 3.4 \\
\hline \multirow[t]{4}{*}{ Seedling fresh weight $(\mathrm{g})$} & $E C^{*}$ & 2.3 & 2.7 & 3.2 & 3.3 & 2.8 \\
\hline & $b$ & 0.058 & 0.051 & 0.053 & 0.055 & 0.058 \\
\hline & $E C_{50}$ & 9.7 & 10.3 & 11.3 & 11.0 & 10.1 \\
\hline & $p$ & 3.3 & 2.8 & 3.0 & 3.1 & 3.3 \\
\hline \multirow[t]{4}{*}{ Seedling dry weight (g) } & $E C^{*}$ & 2.2 & 2.1 & 3.7 & 3.8 & 3.5 \\
\hline & $b$ & 0.056 & 0.053 & 0.050 & 0.051 & 0.054 \\
\hline & $E C_{50}$ & 10.2 & 10.6 & 12.7 & 12.3 & 11.3 \\
\hline & $p$ & 2.9 & 2.6 & 2.9 & 2.9 & 3.0 \\
\hline \multirow[t]{4}{*}{$W M S R(\mathrm{~g})$} & $E C^{*}$ & 4.2 & 6.5 & 4.6 & 3.5 & 3.7 \\
\hline & $b$ & 0.054 & 0.058 & 0.054 & 0.050 & 0.054 \\
\hline & $E C_{50}$ & 12.5 & 14.7 & 13.0 & 12.9 & 12.2 \\
\hline & $p$ & 3.4 & 3.9 & 3.2 & 2.8 & 2.9 \\
\hline
\end{tabular}

1 final maximum emergence $\left(E_{\max }\right)$, emergence rate based on the rate reaching $50 \%$ emergence $\left(R_{50}\right)$, reciprocal of the emergence uniformity $(R E U)$, vitality index $(V I)$, weight of mobilized seed reserve (WMSR).

2 salinity threshold at which the reduction begins $\left(E C^{*}\right)$, reduction slope in response to salinity $(b), E C$ at which trait is reduced by 50 percent $\left(E C_{50}\right)$, dimensionless empirical shape parameter $(p)$.

${ }^{3}$ control (Con), ascorbic acid (Asc), proline (Pro), potassium silicate $\left(\mathrm{K}_{2} \mathrm{SiO}_{3}\right)$, spermidine (Spd), Lake Urmia saline water (LUsw).

threshold $E C$ changed, with the changes not being the same among the different seed priming agents. As an example, Fig. 4 visually shows the effects of salinity on seedling growth for the control and the $\mathrm{K}_{2} \mathrm{SiO}_{3^{-}}$ treated seeds.

In general, all priming agents considerably alleviated the adverse effects of salinity (Fig. 3). The positive effects of seed priming in our study can be considered from two perspectives: $i$ ) lessening the rate of the salinity-induced decline of the traits, and ii) delaying the start of the declining trend in the measured traits. Priming was more efficient in term of the second perspective.

The effects of salinity and seed priming on the various traits were analyzed next in terms of the numerical salinity response functions. Fig. 5 shows the overall fit of the salinity response functions for $E_{\max }$, $R_{50}$, VI and seedling dry weight for both the control and priming with $\mathrm{K}_{2} \mathrm{SiO}_{3}$, the latter being the most efficient priming agent. Relative values of the traits remained more or less constant until they reached some threshold $E C$, beyond which they decreased.

A box plot of the Akaike information criterion $(A I C)$ for the response functions over all of the traits considered showed that the van Genuchten and Hoffman (1984) response function had the lowest AIC values, followed by the Maas and Hoffman (1977) and Dirksen et al. (1993) functions (Fig. 6). Mean and median AIC values for the van

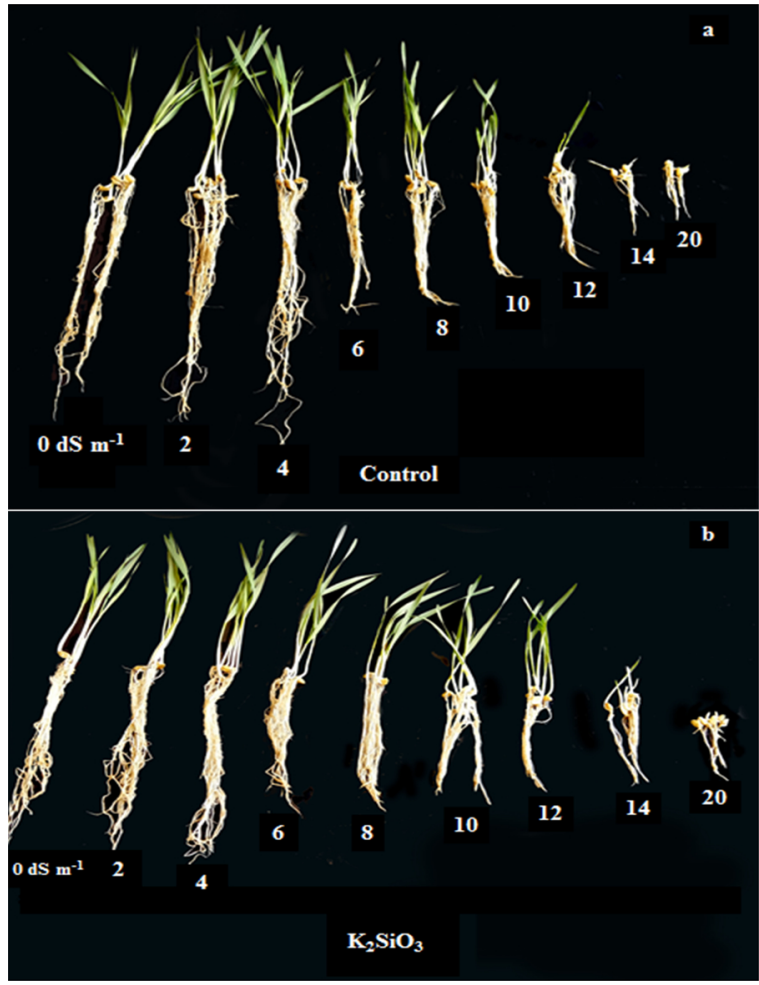

Fig. 4. Seedling growth of wheat in response to different concentrations of salinity for (a) the control (no seed priming), and (b) primed with $\mathrm{K}_{2} \mathrm{SiO}_{3}$. A considerable effect of seed priming was observed for intermediate salinities (i.e., for salinity levels of between 6 and $12 \mathrm{dS} \mathrm{m}^{-1}$ ).

Genuchten and Hoffman (1984) and the Maas and Hoffman (1977) functions were -33.9 and -34.6 and -23.9 and -25.6 , respectively. The mean and median AIC values were, respectively, -18.1 and -17.5 for the Dirksen et al. (1993) function. The first to third quartile values of the AIC for the van Genuchten and Hoffman (1984) function were within the range of -38.8 to -29.9 , while they varied from -29.5 to -19.9 for the Maas and Hoffman (1977) function, and from -24.7 to -13.0 for the Dirksen et al. (1993) response function (Fig. 6). While there was generally no statistically significant difference between either the Maas and Hoffman (1977) and the Dirksen et al. (1993) functions or the van Genuchten and Hoffman (1984) and Maas and Hoffman (1977) functions in terms of their AIC values $(P \geq 0.05)$, the van Genuchten and Hoffman (1984) response function provided fits that were statistically superior $(P<0.05)$ to the Dirksen et al. (1993) function. Table 1 lists, for all five priming agents, the fitted parameters of the van Genuchten and Hoffman $\left(E C_{50}\right.$ and $\left.p\right)$ and Maas and Hoffman ( $E C^{*}$ and b) response functions.

\subsection{Quantitative effects of seed priming on plant response to salinity}

Increasing the salinity caused the values for all emergence indices to decrease for the control and all priming agent. For example, $E_{\max }$ for the control began to decrease at $E C=12.3 \mathrm{dS} \mathrm{m}^{-1}\left(E C^{*}\right)$ and was lowered by 50 percent $\left(E C_{50}\right)$ at $E C=16.2 \mathrm{dS} \mathrm{m}^{-1}$. This trait was the least affected by salinity (see also Fig. 5a). We note here that all seed priming agents improved seed emergence such that the average $E C^{*}$ and $E C_{50}$ values increased to 15.6 and $17.3 \mathrm{dS} \mathrm{m}^{-1}$, respectively. The most effective seed priming agents for $E_{\max }$ was $\mathrm{K}_{2} \mathrm{SiO}_{3}$, which increased $E C *$ to $16.2 \mathrm{dS} \mathrm{m}^{-1}$ and $E C_{50}$ to $17.7 \mathrm{dS} \mathrm{m}^{-1}$.

The lowest $E C^{*}$ value of the emergency rate $\left(R_{50}\right)$ was observed for seedlings of the control $\left(E C^{*}=1.6 \mathrm{dS} \mathrm{m}^{-1}\right)$, and the highest value for $\mathrm{K}_{2} \mathrm{SiO}_{3}$-treated seedlings $\left(2.1 \mathrm{dS} \mathrm{m}^{-1}\right)$. On the other hand, seed priming decreased the seedling sensitivity to salinity by increasing $E C^{*}$ for $R_{50}$. 

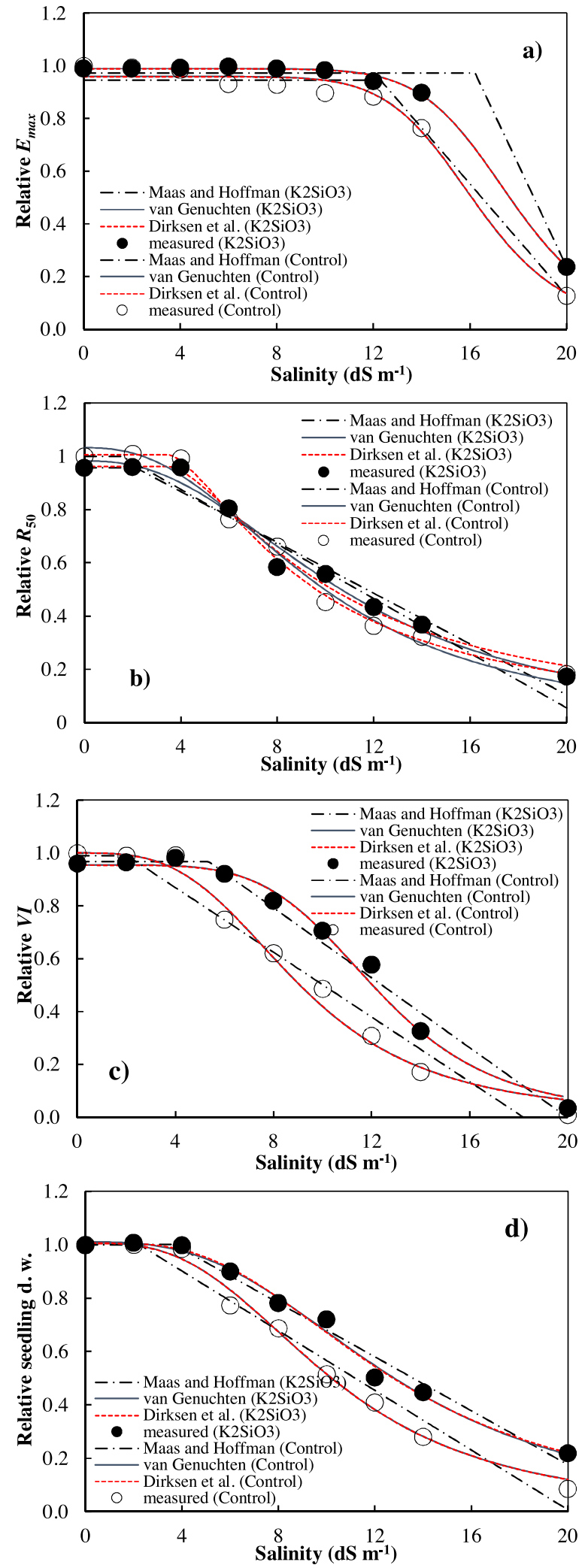

Fig. 5. Overall fit of the applied response functions to the experimental data for $E_{\max }$ (a), $R_{50}$ (b), $V I$ (c) and seedling dry weight (d) versus salinity for the control and the $\mathrm{K}_{2} \mathrm{SiO}_{3}$ primed seeds.

$R_{50}$ of the control seedlings decreased by 50 percent $\left(E C_{50}\right)$ at $E C=9.7 \mathrm{dS} \mathrm{m}^{-1}$, while the $E C_{50}$ values for Pro, $\mathrm{K}_{2} \mathrm{SiO}_{3}$, Spd and LUsw were $9.7,10.8,9.9$ and $10.3 \mathrm{dS} \mathrm{m}^{-1}$, respectively (Table 1 ). Among the seed priming agents, only $\mathrm{K}_{2} \mathrm{SiO}_{3}$ slightly decreased the value of $b$ for

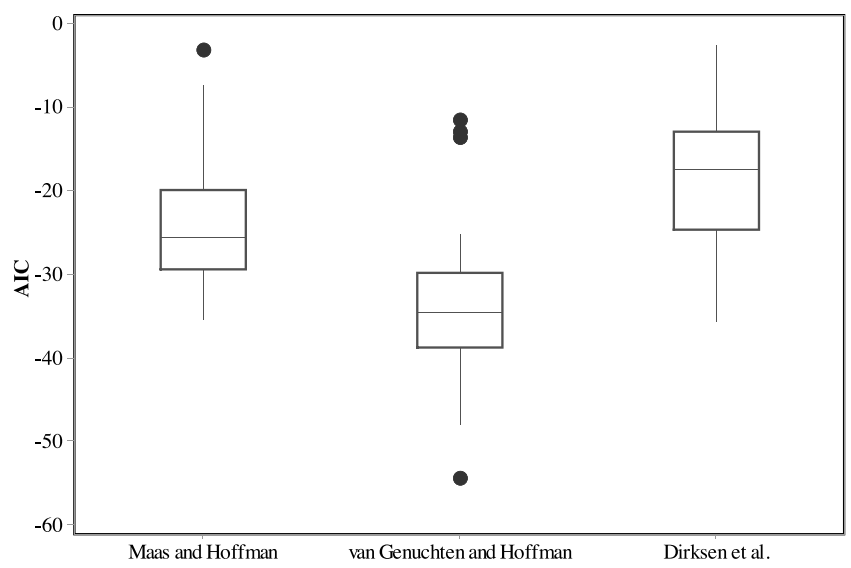

Fig. 6. Box plot of the Akaike information criterion (AIC) values for comparison among the response functions used, as averaged over all of the traits studied.

$R_{50}$. Nonetheless, $b$ for $R_{50}$ increased with other priming agents. Consequently, a comparison of the parameters for $E_{\max }$ and $R_{50}$ showed that the sensitivity of $R_{50}$ to salinity was more than $E_{\max }$. Besides, the ability of seed priming to alleviate the adverse effects of salinity on $E C_{50}$ of both traits was very similar. Still, the greater difference between $E C^{*}$ of the control and the primed seeds for $E_{\max }$, as compared to $R_{50}$, indicates that seed priming was more efficient in reducing the adverse effects of salinity on $E_{\max }$.

A comparison of reciprocal emergence uniformity ( $R E U$ ) values as affected by seed priming shows that all priming agents had very little effect. $E C *$ and $E C_{50}$ increased only with $\mathrm{K}_{2} \mathrm{SiO}_{3}$ and $\mathrm{Spd}$. $R E U$ values obtained with Pro and LUsw priming showed slightly lower $E C_{50}$ values compared to the control. Also, $b$ of $R E U$ using Pro as the priming agent decreased slightly while increasing for the other priming agents relative to the control.

$E C^{*}$ and $E C_{50}$ for the control vitality index (VI) were 2.2 and $9.3 \mathrm{dS} \mathrm{m}^{-1}$, respectively. The positive effect of priming on $V I$ is shown by the increased values of $E C^{*}$ and $E C_{50} . \mathrm{K}_{2} \mathrm{SiO}_{3}$ and LUsw had the most and least effect on $E C^{*}$ (151 \% and $53 \%$ higher than the control $E C^{*}$, respectively). Furthermore, priming raised $E C_{50}$ by an average of $11.1 \mathrm{dS} \mathrm{m}^{-1}$, of which $\mathrm{K}_{2} \mathrm{SiO}_{3}$ and Spd exceeded the average. On the other hand, $b$ increased when using $\mathrm{K}_{2} \mathrm{SiO}_{3}$, Pro and Spd, but decreased with LUsw priming.

Increasing the salinity caused seedling length to decrease. A possible reason for reducing seedling length, one of emergence indices, may be due to lowering the turgor pressure at relatively high salinities as a consequence of slowing down water uptake by the seedlings, which should reduce cell enlargement (Migahid et al., 2019) and may shorten the shoot (Izzo et al., 1991). Another probable reason is a reduction in the mobilized seed reserve (WMSR). During seed germination under salinity, not only seed reserve utilization decreases, but also its efficiency, because of increased respiration so that the dry weight of growing seedlings always became lower than that of the mobilized substrates (Chen and Arora, 2011). However, seed priming had a positive effect on seedling length. As an example, $E C^{*}$ for seedling length increased up to 24, 97, 33 and $36 \%$ using Pro, $\mathrm{K}_{2} \mathrm{SiO}_{3}$, Spd and LUsw, respectively, compared to the control. By comparison, the value of $b$ was not significantly affected by priming. Seed priming similarly increased $E C_{50}$ of seedling length by an average of $17 \%$ relative to the control $E C_{50}$. The effects of Pro and $\mathrm{K}_{2} \mathrm{SiO}_{3}$ on seedling length were, respectively, the least and most significant compared to the other seed priming agents.

The adverse effects of salinity on seedling fresh weight were compensated by increasing $E C^{*}$ and $E C_{50}$ for all seed priming agents. Seedling fresh weight for the control was not affected by $E C$ up to $2.3 \mathrm{dS} \mathrm{m}^{-1}$. The highest $E C^{*}$ and $E C_{50}$ values (the averages increased 41 and $15 \%$, respectively) were obtained using Spd and $\mathrm{K}_{2} \mathrm{SiO}_{3}$. 
The $E C^{*}$ and $E C_{50}$ values of seedling dry weight, which for the control were 2.2 and $10.2 \mathrm{dS} \mathrm{m}^{-1}$, respectively, increased also with seed priming (except for $E C^{*}$ for Pro). The highest increases of $E C^{*}$ and $E C_{50}$ (72 and $24 \%$, respectively) were obtained with Spd and $\mathrm{K}_{2} \mathrm{SiO}_{3}$. Although Pro reduced $E C^{*}$ by $0.1 \mathrm{dS} \mathrm{m}^{-1}$, it increased $E C_{50}$ of seedling dry weight by $0.4 \mathrm{dS} \mathrm{m}^{-1}$ and decreased $b$ by 0.003 . Other seed priming agents reduced $b$ as well.

The most significant differences between the various seed priming agents were obtained for the weight of the mobilized seed reserve (WMSR), especially in terms of $E C^{*}$, but also $E C_{50}$ (Table 1). While WMSR declined with salinity for all seed priming agents and the control, the salinity thresholds for Spd and LUsw were less than those of the control and the other priming agents. By comparison, WMSR for Pro had the highest $E C^{*}$ and $E C_{50}$, values $\left(6.5\right.$ and $14.7 \mathrm{dS} \mathrm{m}^{-1}$, respectively). Although the positive effect of $\mathrm{K}_{2} \mathrm{SiO}_{3}$ for $W M S R$ was not as much as those of Pro, $\mathrm{K}_{2} \mathrm{SiO}_{3}$ priming was able to increase $E C^{*}$ and $E C_{50}$ by 10 and $4.1 \%$, respectively. $b$ only increased by Pro. Our WMSR findings are in agreement with recent studies by Bhanuprakash and Yogeesha (2016), who reported that seed priming increased seed reserve utilization, seedling dry weight and the seed reserve depletion of mountain rye and wheat.

The seed priming agents in most cases positively changed $E C^{*}, b$ and $E C_{50}$ for emergence and the other seedlings qualities, although each priming agent had its unique impact on the traits. As a general trend, the effect of seed priming was most pronounced for the $E C^{*}$ and $E C_{50}$ indices. Values of $E C^{*}$ seemed to have been influenced by seed priming more than the other parameters, with the highest increases occurring for the vitality index ( $83 \%$ ) and seedling length (48\%). However, all seed priming agents had a positive effect on the seedling traits, with $\mathrm{K}_{2} \mathrm{SiO}_{3}$ being the best. Paul et al. (2017) and Shi et al. (2014) concluded that improvements of seed germination and reductions in the effects of oxidative stress on seedlings primed with $\mathrm{Spd}$ and $\mathrm{Si}$ were due to boosting the antioxidant defense. Our findings on the valuable effects of seed priming are consistent also with those reported by Anaya et al. (2018) for broad bean and Patanè et al. (2009) for sweet sorghum.

When averaged over all the traits, seed priming increased the minimum, maximum and mean salinity thresholds, $E C^{*}$, compared to the control (Table 1). For the most effective priming agent $\left(\mathrm{K}_{2} \mathrm{SiO}_{3}\right)$, these cardinal points were $2.0,16.2$ and $5.3 \mathrm{dS} \mathrm{m}^{-1}$, respectively, compared to $0.0,12.3$ and $3.4 \mathrm{dS} \mathrm{m}^{-1}$ for the control (Table 1). Similar increases, although less pronounced, were observed for all other priming agents. For example, the $E C^{*}$ values averaged over all traits increased to 4.5, 4.7, and $4.2 \mathrm{dS} \mathrm{m}^{-1}$ for the Pro, Spd and LUsw priming agents, respectively. Moreover, the minimum and maximum $E C_{50}$ for the control treatment, which were 8.6 and $16.2 \mathrm{dS} \mathrm{m}^{-1}$, respectively, were 8.6 and $17.7 \mathrm{dS} \mathrm{m}^{-1}$ for $\mathrm{K}_{2} \mathrm{SiO}_{3}$, the most effective pretreatment (Table 1). But all seed priming agents had a positive effect: the mean $E C_{50}$ as averaged over all traits increased from 10.8 for the control to $11.4,12.4,11.9$, and $11.4 \mathrm{dS} \mathrm{m}^{-1}$ for the Pro, $\mathrm{K}_{2} \mathrm{SiO}_{3}$, Spd and LUsw priming agents, respectively. Among the various traits, the mean $E C^{*}$ and $E C_{50}$ (again, as averaged over all seed priming agents) improved most for the vitality index (VI), seedling length and seedling dry weight. Interestingly, the entries in Table 1 show that seed priming in general had little effect on the $p$ value of the van Genuchten and Hoffman (1984) salinity response function (Eq. 2), although some exceptions are apparent (especially for $E_{\max }$ ). The average value of $p$ for most cases remained very close to 3.0 as noted by van Genuchten and Gupta (1993) for many crops.

\section{Conclusions}

Our study showed that seed priming improved the salt tolerance of wheat seedlings. This was supported by increasing values of several traits under salinity stress. Seed priming increased the vitality index, seedling length and seedling dry weight compared to other traits, improved the development of seedlings, and mitigated the effects of salinity stress. The principle purpose of this study was to quantitatively analyze seedling response to the simultaneous effects of salinity and seed priming. Analyses of our data showed that the salinity response functions of van Genuchten and Hoffman (1984) and Maas and Hoffman (1977) were able to describe the response of seedlings to salinity and seed priming with remarkable accuracy. The functions and their parameters provided useful insight into the overall effects of priming and salinity, including showing that $\mathrm{K}_{2} \mathrm{SiO}_{3}$ was the most effective priming agent.

While overall findings of our study confirmed the positive effects of seed priming on seed germination and establishment under saline conditions, more investigations on plant response to salinity and priming are needed, not only during early growth stages and using salinized soils (in our case we used saline water from Lake Urmia), but also with naturally salinized soils and for different environments. Especially needed are studies investigating whether the positive effects of seed priming on growth can be extrapolated to entire growth periods. Results of such studies covering the complete plant life cycle would provide much practical information for crop management in saline environments.

\section{Declaration of Competing Interest}

The authors declare that they have no known competing financial interests or personal relationships that could have appeared to influence the work reported in this paper.

\section{References}

Abu El-Soud, W., Hegab, M.M., Abd Elgawad, H., Zinta, G., Asard, H., 2013. Ability of ellagic acid to alleviate osmotic stress on chickpea seedlings. Plant Physiol. Biochem. 71, 173-183.

Ali, Q., Daud, M.K., Haider, M.Z., Ali, S., Rizwan, M., Aslam, N., Noman, A., Iqbal, N., Shahzad, F., Deeba, F., Ali, I., Zhu, S.J., 2017. Seed priming by sodium nitroprusside improves salt tolerance in wheat (Triticum aestivum L.) by enhancing physiological and biochemical parameters. Plant Physiol. Biochem. 119, 50-58.

Ahmed, M., Qadeera, U., Ahmed, Z.I., Hassan, F., 2016. Improvement of wheat (Triticum aestivum) drought tolerance by seed priming with silicon. Arch. Agron. Soil Sci. 62 (3), 299-315.

Anaya, F., Fghire, R., Wahbi, S., Loutfi, K., 2018. Influence of salicylic acid on seed germination of Vicia Faba L. under salt stress. J. Saudi Soc. Agric. Sci. 17 (1), 1-8.

Bajwa, A.A., Farooq, M., Nawaz, A., 2018. Seed priming with sorghum extracts and benzyl aminopurine improves the tolerance against salt stress in wheat (Triticum aestivum L.). Physiol. Mol. Biol. Plants 24 (2), 239-249.

Bhanuprakash, K., Yogeesha, H.S., 2016. Seed priming for abiotic stress tolerance: an overview. In: Srinivasa Rao, N.K., Shivashankara, K.S., Laxman, R.H. (Eds.), Abiotic Stress Physiology of Horticultural Crops. Springer, pp. 103-117.

Bojović, B., Đelić, G., Topuzović, M., Stanković, M., 2010. Effects of $\mathrm{NaCl}$ on seed germination in some species from families Brassicaceae and Solanaceae, Kragujevac J, Sci . 32, 83-87.

Bolster, C.H., Hornberger, G.M., 2007. On the use of linearized Langmuir equations. Soil Sci. Soc. Am. J. 71 (6), 1796-1806.

Chen, K., Arora, R., 2011. Dynamics of the antioxidant system during seed osmopriming, post-priming germination and seedling establishment in spinach (Spinacia oleracea). Plant Sci. 180 (2), 212-220.

Dirksen, C., Kool, J.B., Koorevaar, P., van Genuchten, M.Th., 1993. HYSWASOR, simulation model of hysteretic water and solute transport in the root zone. In: Yaron, D., Dagan, G. (Eds.), Water Flow and Solute Transport in Soils. Springer, New York, pp. 99-122.

Geng, A., Wang, X., Wu, L., Wang, F., Wu, Z., Yang, H., Chen, Y., Wen, D., Liu, X., 2018. Silicon improves growth and alleviates oxidative stress in rice seedlings (Oryza sativa L.) by strengthening antioxidant defense and enhancing protein metabolism under arsanilic acid exposure. Ecotoxicol. Environ. Saf. 158, 266-273.

Hua-Long, L., Han-Jing, S., Jing-Guo, W., Yang, L., De-Tang, Z., Hong-Wei, Z., 2014 Effect of seed soaking with exogenous proline on seed germination of rice under salt stress. J. Northeast Agric. Univ. 21 (3), 1-6.

Ibrahim, E.A., 2016. Seed priming to alleviate salinity stress in germinating seeds. J. Plant Physiol. 192, 38-46.

Jaafer, M.Z., Farooq, M., Cheema, M., Afzal, I., Basra, S.M.A., Wahid, M.A., Aziz, T, Shahid, M., 2012. Improving the performance of wheat by seed priming under saline conditions improving the performance of wheat by seed priming under saline conditions. J. Agron. Crop Sci. 198, 37-45.

Jiménez-Arias, D., Borges, A.A., Luis, J.C., Valdés, F., Sandalio, L.M., Pérez, J.A., 2015. Priming effect of menadione sodium bisulphite against salinity stress in arabidopsis involves epigenetic changes in genes controlling proline metabolism. Environ. Exp. Bot. 120, 23-30.

Kang, S., Post, W.M., Nichols, J.A., Wang, D., West, T.O., Bandaru, V., Izaurralde, R.C., 
2013. Marginal lands: concept, assessment and management. J. Agric. Sci. 5 (5), 129-139.

KhoshKholgh Sima, N.A., Alitabar, R., Eqbalinejad, M., Babazadeh, P., Taleh Ahmad, S., 2013. Effect of salinity on germination and threshold salinity in barley. Iran. J. Field Crop Res. 11 (1), 107-120.

Kopittke, P.M., Menzies, N.W., Wang, P., McKenna, B.A., Lombi, E., 2019. Soil and the intensification of agriculture for global food security. Environ. Int. 132, 105078.

Kovácik, J., Klejdus, B., Hedbavny, J., Backor, M., 2009. Salicylic acid alleviates NaClinduced changes in the metabolism of matricaria chamomilla plants. Ecotoxicology 18 (5), 544-554.

Li, Z., Peng, Y., Zhang, X.Q., Ma, X., Huang, L.K., Yan, Y.H., 2014. Exogenous spermidine improves seed germination of white clover under water stress via involvement in starch metabolism, antioxidant defenses and relevant gene expression. Molecules 19, $18003-18024$.

Maas, E.V., Hoffman, C.J., 1977. Crop salt tolerance-current assessment. J. Irrig. Drain. Div. 103, 110-134.

Migahid, M.M., Elghobashy, R.M., Bidak, L.M., Amin, A.W., 2019. Priming of Silybum marianum (L.) Gaertn seeds with $\mathrm{H}_{2} \mathrm{O}_{2}$ and magnetic field ameliorates seawater stress. Heliyon 5 (6), e01886.

Maggio, A., De Pascale, S., Angelino, G., Ruggiero, C., Barbieri, G., 2004. Physiological response of tomato to saline irrigation in long-term salinized soils, Europ. J. Agronomy . 21 (2), 149-159.

Munns, R., Gilliham, M., 2015. Salinity tolerance of crops - what is the cost? New Phytol. 208, 668-673.

Patanè, C., Cavallaro, V., Cosentino, S.L., 2009. Germination and radicle growth in unprimed and primed seeds of sweet sorghum as affected by reduced water potential in $\mathrm{NaCl}$ at different temperatures. Ind. Crop Prod. 30, 1-8.

Paul, S., Roychoudhury, A., Banerjee, A., Chaudhuri, N., Ghosh, P., 2017. Seed pretreatment with spermidine alleviates oxidative damages to different extent in the salt ( $\mathrm{NaCl}$ )-stressed seedlings of three indica rice cultivars with contrasting level of salt tolerance Saikat. Plant Gene 11, 112-123.

Razzaghi, S., Khodaverdiloo, H., Ghorbani Dashtaki, S., 2016. Effects of long-term wastewater irrigation on soil physical properties and performance of selected infiltration models in a semi-arid region. Hydrol. Sci. J. 61 (10), 1778-1790.

Saadat, S., Homaee, M., 2015. Modeling sorghum response to irrigation water salinity at early growth stage. Agr. Water Manag. 152, 119-124.

Sadeghi, H., Robati, Z., 2015. Response of cichorium intybus L. to eight seed priming methods under osmotic stress conditions. Biocatal. Agric. Biotechnol. 4 (4), 443-448.

Saddiq, M.S., Iqbal, S., Afzal, I., Ibrahim, A.M.H., Bakhtavar, M.A., Hafeez, M.B., Maqbool, J., Maqbool, M.M., 2019. Mitigation of salinity stress in wheat (Triticum aestivum L.) seedlings through physiological seed enhancements. J. Plant Nutr. 42 (10), 1-13.
Sajirani, B.E., Shakouri, M.J., Mafakheri, S., 2011. Borage (Borago Officinalis L.) germination under saline condition. Ann. Biol. Res. 2 (6), 414-416.

Shi, Y., Zhang, Y., Yao, H., Wu, J., Sun, H., Gong, H., 2014. Silicon improves seed germination and alleviates oxidative stress of bud seedlings in tomato under water deficit stress. Plant Physiol. Biochem. 78, 27-36.

Sivritepe, N., Sivritepe, H.O., Eris, A., 2003. The effect of $\mathrm{NaCl}$ priming on salt tolerance in melon seedlings grow under saline conditions. Sci. Hortic. 97, 229-237.

Smedema, L.K., Shiati, K., 2002. Irrigation and salinity: a perspectivereview of the salinity hazards of irrigation development in the arid zone. Irrigat. Drain. Syst. 16 (2), $161-174$.

Steppuhn, H., van Genuchten, M.Th., Grieve, C.M., 2005. Root-zone salinity: I. Selecting a product - yield index and response function for crop tolerance. Crop Sci. 45, 209-220.

Subramanyam, K., Laing, G.D., Van Damme, E.J.M., 2019. Sodium selenate treatment using a combination of seed priming and foliar spray alleviates salinity stress in rice. Front. Plant Sci. 10, 1-17.

Tahjib-Ul-Arif, M., Roy, P.R., Sohag, A.A.M., Afrin, S., Rady, M.M., Hossain, M.A., 2018. Exogenous calcium supplementation improves salinity tolerance in BRRI Dhan28; a salt susceptible high-yielding Oryza sativa cultivar. J. Crop Sci. Biotech. 21 (4), 383-394.

Taie, H.A.A., Abdelhamid, M.T., Dawood, M.G., Nassar, R.M.A., 2013. Pre-sowing seed treatment with proline improves some physiological, biochemical and anatomical attributes of faba bean plants under sea water. J. Appl. Sci. Res. 9 (4), 2853-2867.

Takemura, Y., Satoh, M., Satoh, K., Hamada, H., Sekido, Y., Kubota, S., 2010. High dose of ascorbic acid induces cell death in mesothelioma cells. Biochem. Biophys. Res. Commun. 394 (2), 249-253.

Torabi, F., Majd, A., Enteshari, S., 2012. Effect of exogenous silicon on germination and seedling establishment in Borago Officinalis L. J. Med. Plant Res. 6 (10), 1896-1901.

Tuna, A.L., Kaya, C., Higgs, D., Murillo-Amador, B., Aydemir, S., Girgin, A.R., 2008. Silicon improves salinity tolerance in wheat plants. Environ. Exp. Bot. 62, 10-16.

van Genuchten, M.Th., Gupta, S.K., 1993. A reassessment of the crop response function. J. Indian Soc. Soil Sci. 41, 730-737.

van Genuchten, M.Th., Hoffman, G.J., 1984. Management aspect for crop production. In: Shainberg, I., Shalhevet, J. (Eds.), Soil Salinity Under Irrigation. Springer, New York, pp. 258-271.

van Genuchten, M.Th., 1983. Analyzing Crop Salt Tolerance Data: Model Description and User's Manual. Research Report No. 120, U.S. Salinity Laboratory, USDA-ARS, 50 pp. Riverside, CA.

Wang, W.B., Kim, Y.H., Lee, H.S., Kim, K.Y., Deng, X.P., Kwak, S.S., 2009. Analysis of antioxidant enzyme activity during germination of alfalfa under salt and drought stresses. Plant Physiol. Biochem. 47 (7), 570-577. 